A) Check for updates

Cite this: Analyst, 2020, 145, 4212

\section{Changes in latent fingermark glyceride composition as a function of sample age using UPLC-IMS-QToF-MS ${ }^{\mathrm{E}}$}

\author{
Amanda A. Frick, (D) *a Natalie Kummer, (DD ${ }^{b}$ Ana Moraleda (iD ${ }^{b}$ and \\ Céline Weyermann (D)*b
}

\begin{abstract}
The composition of fingermark residue has been an important topic in forensic science, mainly in efforts to better understand and eventually improve the efficacy of latent fingermark detection methods. While the lipid fraction has been extensively studied, there is currently little information about how the glyceride fraction of latent fingermarks is chemically altered over time following deposition. A previously reported untargeted ultra performance liquid chromatography-ion mobility spectrometry-quadrupole time-offlight mass spectrometry (UPLC-IMS-QTOF-MSE) method was used to investigate changes over time in fingermark di- and triglycerides. Charged latent fingermark samples from 5 donors were analysed up to 28 days following deposition. Significant changes in glyceride composition occurred with increased sample age, attributed primarily to the oxidation of unsaturated triglycerides through ozonolysis. Considerably fewer unsaturated TGs were identified in samples 7 and 28 days following deposition, while mono- and diozonides of these lipids were identified as major components of aged samples. Additional compounds were identified as possible aldehyde and carboxylic acid derivatives resulting from the reaction of water with ozonolysis intermediates. While the onset of these processes occurred rapidly following deposition, continuing oxidation over time was seen via the progressive ozonolysis of diunsaturated triglycerides. These results represent a further step towards understanding the factors affecting fingermark composition, ageing and subsequent detection under operational conditions.
\end{abstract}

Received 21st February 2020, Accepted 29th April 2020

DOI: 10.1039/d0an00379d

rsc.li/analyst these processes can depend on a number of factors, including the type of surface (porous or non-porous) on which the fingermark is deposited, the environmental conditions to which the fingermark is exposed (e.g. temperature, humidity, light), and the initial composition of the residue., ${ }^{5,10,14-18}$ As a result, depending on the above factors and the amount of time that has elapsed since deposition, fingermark detection may become more difficult, as the target compounds are transformed or removed, or the bulk residue no longer possesses physical properties compatible with the detection method (e.g. viscosity and adhesiveness). ${ }^{6,14,19}$ Additionally, the fingermark pattern itself can be affected due to 'drying' of the residue resulting in the loss of ridge continuity, ${ }^{20}$ or diffusion of certain fingermark components through or across the substrate. ${ }^{14,19,21}$

The sebaceous lipids largely comprise what is referred to as the 'fragile' or 'labile' fraction of the water-insoluble fingermark constituents. ${ }^{22,23}$ Unlike the more durable 'robust' fraction (large, insoluble proteins and lipoproteins), the labile fraction is readily oxidised and eventually degraded to volatile organic compounds, depending on environmental conditions. ${ }^{3,22,24-26}$ Several broad trends have been identified regarding the lower molecular weight and unsaturated lipid

\footnotetext{
${ }^{a}$ Department of Applied Sciences, Northumbria University, Newcastle upon Tyne, NE1 8ST, UK. E-mail: amanda.frick@northumbria.ac.uk

${ }^{b}$ École des Sciences Criminelles, Université de Lausanne, Batochime, 1015 Lausanne, Switzerland. E-mail: celine.weyermann@unil.ch
} 
components. The rapid oxidation of squalene, a highly unsaturated compound, has been observed in many investigations into fingermark lipid degradation. ${ }^{4-6,16,18,27}$ The rate of squalene loss is accelerated by light exposure. ${ }^{5,27}$ Cholesterol has been shown to decrease at a slower rate. ${ }^{16}$ Further indications as to the kinds of chemical changes undergone by latent fingermark residue may be found in dermatological research, which is concerned primarily with in situ skin surface lipids. Ozonolysis and photo-oxidation of squalene, cholesterol and unsaturated fatty acids have been observed to take place on the skin surface. ${ }^{24,28-30}$

For the most part, investigations into latent fingermark ageing have not utilised approaches amenable to large, neutral lipids, and so it is unclear what chemical changes are undergone by these compounds, and how this may impact upon fingermark detection. Glycerides (including mono-, di- and triglycerides) comprise approximately $30 \%$ of total skin surface lipids, making them one of the major lipid classes in latent fingermark residue. ${ }^{31,32}$ The ageing processes of these compounds are relevant to a variety of fingermark detection techniques, particularly on wetted substrates, where other targets, such as amino acids, may have been removed. ${ }^{33,34}$ While several possible explanations of glyceride degradation exist, few are based on direct observation in fingermark samples.

Archer et al. reported that the concentrations of most free fatty acids appeared to undergo an initial increase, followed by a subsequent decrease over a 33 day period. ${ }^{5}$ They hypothesised that there might be competing mechanisms of fatty acid generation and degradation. The free fatty acids in human skin surface lipids are derived from triglycerides (TGs) secreted by the sebaceous glands. ${ }^{35-37}$ Facultative anaerobes are responsible for the hydrolysis of sebaceous TGs to diglycerides (DGs), monoglycerides (MGs) and free fatty acids within the secretion ducts of the sebaceous glands. ${ }^{38-40}$ Skin flora from multiple genera may be deposited onto a surface through contact with friction ridge skin. ${ }^{41}$ It has therefore been proposed that under certain storage conditions, these bacteria could survive in latent fingermark residue such that enzymatic processes would continue to affect the initial fingermark composition. ${ }^{1,3}$ The degradation of unsaturated free fatty acids (namely 16:1 and 18:1) has been reported by other researchers, ${ }^{3,6}$ however the trend described by Archer et al. was not observed. Conversely, Weyermann et al. found no significant changes in free fatty acid concentration. ${ }^{16}$

Unsaturated sebaceous TGs can contain as many as 9 double bonds, providing multiple target sites for oxidation. ${ }^{42-44}$ Mong et al. observed that with increased age, latent fingermark residues appeared to become solidified and less receptive to staining by histological dyes. This was attributed to autooxidation of the unsaturated TGs, via mechanisms postulated to be similar to that of drying oils. ${ }^{6}$ Such processes involve the formation of glyceride hydroperoxides, followed by crosslinking to form insoluble polymers, ${ }^{45,46}$ but this has never been described in latent fingermarks. Johnston and Rogers similarly inferred that increases in the $\mathrm{OH}$ stretch band in fingermarks subjected to elevated temperatures may be due in part to the oxidation of unsaturated TGs. ${ }^{47}$ More recently, Pleik et al. described the formation of ozonides (1,2,4-trioxolanes) from unsaturated TGs under ambient atmospheric conditions. ${ }^{13}$ Storage conditions appeared to affect the reaction rate, with ozonolysis occurring much more slowly when fingermark samples were protected from light and airflow.

The lack of fundamental understanding regarding fingermark ageing means that it is currently difficult to rationally explain how fingermark detectability may be affected by chemical and physical modifications of the latent residue. Amongst the lipid fraction, there is very little information regarding degradation products or intermediates in latent fingermarks that can be attributed to glycerides. It should be noted that many studies into sebaceous lipid oxidation have each focused on only one group of oxidation products (such as hydroperoxides), ${ }^{48}$ and therefore it is uncertain which mechanism(s) take greatest precedence in relation to fingermark residue. We recently reported a method for the untargeted separation and characterisation of latent fingermark glycerides using ultra performance liquid chromatography-ion mobility spectrometry-quadrupole time-of-flight mass spectrometry (UPLC-IMS-QToF-MS ${ }^{\mathrm{E}}$ ). ${ }^{49}$ This data-independent acquisition approach enabled over 100 intact di- and triglycerides to be identified, with only limited prior knowledge of the glyceride species present in fingermark residue. This paper describes the further application of this approach to investigate the changes in glyceride composition over time within fingermark samples from a small donor population. The key aims of this investigation were to determine changes in glyceride profiles with increasing sample age, as well as to identify possible degradation products based on known oxidation mechanisms of these lipids.

\section{Materials and methods}

\section{Chemicals}

Dichloromethane (GC grade; Sigma-Aldrich, Switzerland), acetonitrile (ULC/MS grade; Biosolve, France), water (LC-MS Ultra grade; Honeywell, Germany), 2-propanol (ULC/MS grade; Biosolve, France), formic acid (ULC/MS grade; Biosolve, France), ammonium formate (LC-MS Ultra grade; Fluka, Switzerland), dimyristin (DG 28:0), dipalmitolein (DG 32:2), dipalmitin (DG 32:0), diolein (DG 36:2) and distearin (DG 36:0) (all >99\%; NuChek Prep, Inc, USA), tricaprilin (TG 24:0), tricaprin (TG 30:0), trilaurin (TG 36:0), trimyristin (TG 42:0) and tripalmitin (48:0) (all 99.9\%; Sigma-Aldrich, USA) were used as received.

Stock solutions of glycerides were prepared in dichloromethane. A $1 \mu \mathrm{M}$ glyceride mixture in $2: 1: 1$ isopropanol/ acetonitrile/water was used as a quality control standard. All standard solutions were stored at $-24{ }^{\circ} \mathrm{C}$ before and after analysis to prevent degradation and solvent evaporation.

\section{Sample collection and storage}

Latent fingermark samples were collected from 5 adult donors (27-36 years old) on $25 \mathrm{~mm}$ filter paper circles (Grade 1 quali- 
tative filter paper; Whatman, UK). Donors were asked to refrain from handling food or chemicals, or washing hands 30 minutes prior to sampling, but were otherwise free to carry out normal activities and use of skin products. Donors were asked to provide charged fingermarks by briefly rubbing the middle three fingertips of both hands on their forehead and nose, then rubbing the fingertips of each hand together to homogenise the secretions. Each of the 6 fingertips were pressed gently to individual filter paper circles for approximately ten seconds. Donors were then asked to repeat the charging procedure and deposit a further six samples, providing a total of 60 samples (12 per donor).

9 samples from each donor were stored in open Petri dishes (lined with aluminium foil) on an office desk, allowing exposure to natural light and airflow, for up to 28 days prior to extraction. The remaining 3 samples from each donor were stored in a metal desk drawer (located immediately below the light-exposed samples) in the same manner for 28 days. Sets of clean filter papers were also stored with the samples to provide analytical blanks for both ageing conditions. The office was not climate-controlled, exposing samples to variations in weather conditions. Temperature and humidity dataloggers (Elpro, Switzerland) were placed with samples in each storage location and programmed to record measurements every 30 minutes. The temperature and relative humidity measurements were largely similar for both storage conditions (Table 1) throughout the 28 days. Samples stored on the desk were exposed to elevated temperatures for brief periods during clear mornings, due to direct sun illumination through an adjacent window.

\section{Fingermark extraction}

Of the samples stored on the desk, three randomly chosen samples from each donor were extracted 1, 7 and 28 days after deposition. The samples stored in the desk drawer were extracted 28 days after deposition. The filter papers were individually placed in $1.75 \mathrm{~mL}$ glass screw-top vials (Thermo Fisher Scientific) that had been cleaned by rinsing with dichloromethane and left to air-dry. Samples were immersed in $750 \mu \mathrm{L}$ dichloromethane for 2 minutes, with gentle manual agitation to ensure that the filter papers were completely submerged in the solvent. After 2 minutes, the extract was transferred to a second vial. Sample cleanup was performed by adding $750 \mu \mathrm{L}$ water and vortex mixing before allowing phase separation. The aqueous top layer was discarded, together with a small amount of the organic layer. The remaining extract was

Table 1 Environmental conditions of sample storage locations

\begin{tabular}{lll}
\hline & Desk & Drawer \\
\hline Average temperature $\left({ }^{\circ} \mathrm{C}\right)$ & 24.5 & 24.4 \\
Minimum temperature $\left({ }^{\circ} \mathrm{C}\right)$ & 22.9 & 22.2 \\
Maximum temperature $\left({ }^{\circ} \mathrm{C}\right)$ & 40.8 & 26.2 \\
Average relative humidity (\%) & 29.6 & 29.3 \\
Minimum relative humidity (\%) & 16.7 & 16.2 \\
Maximum relative humidity (\%) & 42.8 & 43.3
\end{tabular}

stored briefly at $-24{ }^{\circ} \mathrm{C}$ to freeze any residual water before transferring the organic layer to a third vial. The extract was evaporated under nitrogen gas until approximately $150 \mu \mathrm{L}$ remained. This residue was transferred to an amber glass vial containing a $250 \mu \mathrm{L}$ glass insert, and further evaporated to dryness. The remaining residue was dissolved in $200 \mu \mathrm{L}$ of 2:1:1 2-propanol/acetonitrile/water with $20 \mathrm{mM}$ ammonium formate.

\section{Chemical analysis}

Chromatographic separation was performed using a Waters Acquity UPLC I-Class system, coupled to a Waters Vion IMS-QToF mass spectrometer equipped with an electrospray ionisation (ESI) source. The UPLC system was equipped with a binary pump, a 96 well autosampler (maintained at $8^{\circ} \mathrm{C}$ ), and a temperature-controlled column compartment. Separation was performed using an Acquity UPLC $\mathrm{CSH} \mathrm{C}_{18}$ column $(2.1 \times$ $100 \mathrm{~mm}, 1.7 \mu \mathrm{m})$, connected to an Acquity UPLC in-line filter to protect the column (both from Waters). The mobile phases were (A) 60:40 acetonitrile/water with $10 \mathrm{mM}$ ammonium formate and 0.1\% formic acid and (B) 90:10 isopropanol/ acetonitrile with $10 \mathrm{mM}$ ammonium formate and $0.1 \%$ formic acid. Gradient parameters are described in Table 2. The flow rate was maintained at $0.4 \mathrm{~mL} \mathrm{~min}^{-1}$ with a column temperature of $55{ }^{\circ} \mathrm{C}$. The injection volume was $1 \mu \mathrm{L}$. Injections of the blank filter paper extracts were run before and after sample sets from each donor to monitor for carryover and contamination.

The ESI source was operated in positive mode at a mass resolving power of $>40000$ FWHM, using the following parameters: the source temperature was set to $120^{\circ} \mathrm{C}$, the desolvation temperature to $600{ }^{\circ} \mathrm{C}$, the cone gas flow to $50 \mathrm{~L} \mathrm{~h}^{-1}$, the desolvation gas flow to $1000 \mathrm{~L} \mathrm{~h}^{-1}$, and the capillary voltage to $2 \mathrm{kV}$. Data were acquired over the $\mathrm{m} / \mathrm{z}$ range of $50-1000$ with a scan time of 0.2 seconds. A $200 \mathrm{ng} \mathrm{mL}^{-1}$ solution of leucine enkephalin ( $\mathrm{m} / \mathrm{z} 556.2766)$ was used as the lock mass reference and infused into the ion source at 5 minutes intervals. Data acquisition was performed using high definition $\mathrm{MS}^{\mathrm{E}}$. The low collision energy was set at $6 \mathrm{eV}$, and the high collision energy ramp at 30-60 eV. Nitrogen was used as the drift gas in the IMS and as the collision gas. Ion mobility and mass calibration were performed using a Major Mix IMS/Tof Calibration Kit (Waters).

Table 2 UPLC mobile phase gradient parameters

\begin{tabular}{lcc}
\hline Time $(\min )$ & $\% \mathrm{~A}$ & $\% \mathrm{~B}$ \\
\hline 0.0 & 60 & 40 \\
2.0 & 57 & 43 \\
2.1 & 50 & 50 \\
12.0 & 46 & 54 \\
12.1 & 30 & 70 \\
18.0 & 1 & 99 \\
19.0 & 1 & 99 \\
19.1 & 60 & 40 \\
21.0 & 60 & 40
\end{tabular}




\section{Data processing}

Data were processed using UNIFI (Waters MS Technologies, Manchester, United Kingdom). Deconvolution and peak picking were performed with $4 \mathrm{D}$ peak detection, with a low energy intensity threshold of 250 counts and a high energy intensity threshold of 100 counts. The fraction of the chromatographic peak width applied during isotope cluster creation and high-to low energy association was 0.5 . The fraction of the drift peak width applied during cluster creation and high-to low energy association were 0.5 .

Identification of TGs and DGs was carried out as described by Frick and Weyermann, using a combination of in silico fragmentation and filtering candidate peaks based on neutral losses of fatty acyl groups plus ammonia. ${ }^{49}$ Based on the fragmentation of TG ozonides reported by Sun et al. and Pleik et al., ${ }^{13,50}$ additional expected neutral losses of ozonised fatty acids $\left(\mathrm{RCO}_{3 n+2} \mathrm{H}+\mathrm{NH}_{3}\right.$, where $n \leq$ double bonds) were calculated to enable identification of TG ozonides (Table 3). Expected neutral losses of peroxidised fatty acids $\left(\mathrm{RCO}_{2 n+2} \mathrm{H}+\right.$ $\mathrm{NH}_{3}$ ) were also incorporated into the data processing method. Candidate $\mathrm{m} / \mathrm{z}$ of the potential oxidised glycerides were compared to calculated values for $\left[\mathrm{M}+\mathrm{NH}_{4}\right]^{+}$of hydroperoxides and ozonides of the unsaturated glycerides identified in previous work. ${ }^{49}$ High energy mass spectra were examined to identify predominant fragment ions corresponding to fatty acid ozonide neutral losses, as well as fragments corresponding to the neutral loss of a fatty acid and ammonia plus the cleavage of the ozonised fatty acid at the trioxolane ring. ${ }^{13,50}$ Finally, all candidate glycerides and glyceride oxi-

Table 3 Calculated neutral losses of ozonides of major unsaturated fatty acids identified in human sebum and latent fingermarks

\begin{tabular}{|c|c|c|c|}
\hline \multirow[b]{2}{*}{ Fatty $\operatorname{acid}(\mathrm{s})$} & \multirow{2}{*}{$\begin{array}{l}\text { CN: } \\
\text { DB }\end{array}$} & \multicolumn{2}{|c|}{ Ozonide neutral loss } \\
\hline & & Formula & Mass (Da) \\
\hline$\Delta 6$-Tetradecenoic acid & 14:1 & $\mathrm{C}_{13} \mathrm{H}_{25} \mathrm{CO}_{5} \mathrm{HNH}_{3}$ & 291.20457 \\
\hline$\Delta 6$-Pentadecenoic acid & $15: 1$ & $\mathrm{C}_{14} \mathrm{H}_{27} \mathrm{CO}_{5} \mathrm{HNH}_{3}$ & 305.22022 \\
\hline $\begin{array}{l}\Delta 6 \text {-Hexadecenoic acid } \\
\text { (sapienic acid) }\end{array}$ & $16: 1$ & $\mathrm{C}_{15} \mathrm{H}_{29} \mathrm{CO}_{5} \mathrm{HNH}_{3}$ & 319.23587 \\
\hline $\begin{array}{l}\text { Heptadecenoic acid ( } \Delta 6 \text { - and } \\
\Delta 8 \text {-heptadecenoic acid) }\end{array}$ & $17: 1$ & $\mathrm{C}_{16} \mathrm{H}_{31} \mathrm{CO}_{5} \mathrm{HNH}_{3}$ & 333.25152 \\
\hline $\begin{array}{l}\text { Octadecenoic acid }(\Delta 8- \\
\text { octadecenoic, oleic and } \\
\text { petroselenic acid) }\end{array}$ & $18: 1$ & $\mathrm{C}_{17} \mathrm{H}_{33} \mathrm{CO}_{5} \mathrm{HNH}_{3}$ & 347.26717 \\
\hline $\begin{array}{l}\text { Octadecadienoic acid (sebaleic } \\
\text { and linoleic acid) }\end{array}$ & $18: 2$ & $\begin{array}{l}\mathrm{C}_{17} \mathrm{H}_{31} \mathrm{CO}_{5} \mathrm{HNH}_{3} \\
\mathrm{C}_{17} \mathrm{H}_{31} \mathrm{CO}_{8} \mathrm{HNH}_{3}\end{array}$ & $\begin{array}{l}345.25152 \\
393.23627\end{array}$ \\
\hline$\Delta 10$-Eicosenoic acid & $20: 1$ & $\mathrm{C}_{19} \mathrm{H}_{37} \mathrm{CO}_{5} \mathrm{HNH}_{3}$ & 375.29847 \\
\hline
\end{tabular}

dation products were required to have a peak response at least 2.5 times higher than that of any corresponding peak in a preceding blank filter paper extract.

\section{Results and discussion}

\section{Nomenclature}

Annotation of glyceride structures in this paper follows the recommendations of Liebisch et al. ${ }^{51}$ Lipid classes (free fatty acids and di- and triglycerides) are denoted as FA, DG and TG, respectively, followed by the $\mathrm{CN}$ :DB family as a generic identifier (where $\mathrm{CN}$ denotes the total number of carbon atoms in the fatty acyl groups and DB the total number of double bonds). In the case of triglyceride ozonides, the convention TG $\mathrm{CN}: \mathrm{DBE} ; \mathrm{O}_{x}$ is used (where DBE (double bond equivalent) indicates the total number of rings and double bonds, and $\mathrm{O}_{x}$ the number of oxygen atoms). As an example, the monoozonide of the diunsaturated triglyceride TG 48:2 would be expressed as TG 48:2; $\mathrm{O}_{3}$, and its diozonide as TG 48:2; $\mathrm{O}_{6}$ (Fig. 1). Where structural information is provided, the separator '_' is used to indicate that the $s n$-positions of the fatty acids (or equivalent derivatives) are unknown.

\section{Changes in glyceride profile with sample age}

As in previously reported work, ${ }^{49}$ fingermark TGs were detected primarily as ammoniated adducts, eluting over a broad range of 6-17 minutes. In total, over 80 families of TGs were identified in 60 fingermark samples, ranging in structure from 28:0-59:2. A summary of the TGs detected in samples 1-28 days after deposition is presented in Table 4 .

The glyceride profiles of 1 day old samples were consistent with previously reported results. ${ }^{49}$ The predominant TGs identified in samples of this age were largely mono and diunsaturated structures, eluting between 15-17 minutes. Saturated

Table 4 Numbers of triglycerides detected in fingermarks from 5 donors in fingermarks 1-28 days following deposition

\begin{tabular}{lllll}
\hline & \multicolumn{2}{l}{ Sample age } \\
\cline { 2 - 5 } & 1 day & 7 days & $\begin{array}{l}28 \text { days } \\
\text { (desk) }\end{array}$ & $\begin{array}{l}\text { 28 days } \\
\text { (drawer) }\end{array}$ \\
\hline Saturated TGs & 26 & 23 & 26 & 25 \\
Monounsaturated TGs & 22 & 10 & 0 & 5 \\
Diunsaturated TGs & 20 & 7 & 4 & 1 \\
Polyunsaturated TGs & 15 & 0 & 0 & 1
\end{tabular}
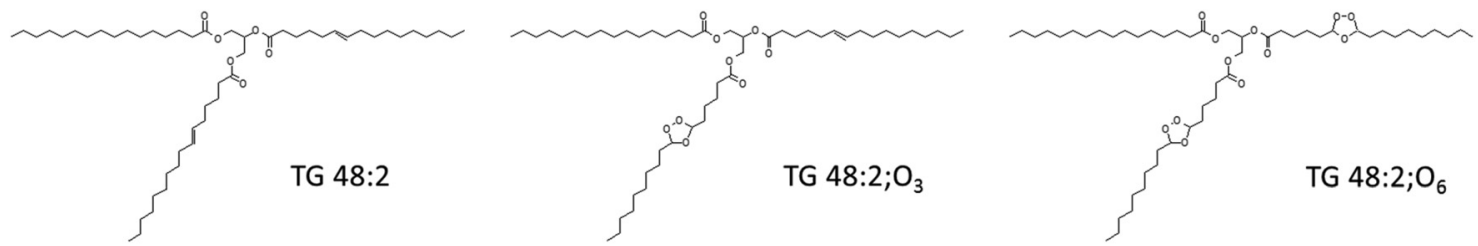

Fig. 1 Example structural annotations of a triglyceride and its ozonides. 

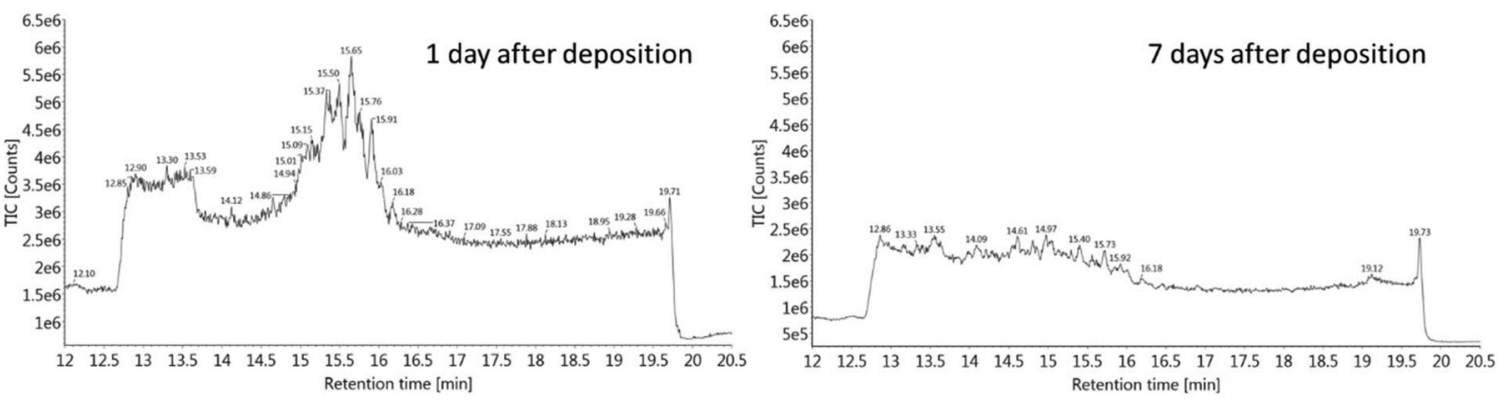

Fig. 2 Total ion chromatograms of UPLC separation of latent fingermark residue from a single donor, showing differences with increasing sample age.

and polyunsaturated TGs (containing up to 4 double bonds) were also present as major glycerides, while DGs were detected as minor components. In four of the five donors, the glycerides exhibiting the greatest peak signal were unsaturated, ranging from 45:1-50:2 in structure. Lower molecular weight glycerides gave greatest peak signals in samples from the fifth donor, comprising mainly saturated TGs in the range of 32:0-40:0.

Samples stored for 7 and 28 days after deposition exhibited a dramatic change in glyceride composition compared to the 1 day old samples (Fig. 2). The predominant TGs in these samples were largely saturated, though some unsaturated TGs were still present at relatively lower levels in some samples. The rapid decrease of unsaturated TGs is consistent with observations made by Zhou et al. ${ }^{26}$ Similarly, Pleik et al. noted the disappearance of TG 48:1 within a few days following fingermark deposition, though persistence appeared to depend on donor influence. ${ }^{13}$ It should be noted that almost all unsaturated TGs identified in samples stored for 7-28 days on the desk originated from a single donor. This donor reported that they had used moisturising cream and cosmetics within 12 hours prior to sample collection. While they were not the only donor who had recently used skin products, samples deposited by this donor contained visible amounts of foundation. The ingredients of the moisturising cream included sources of glycerides such as shea butter, which may have contributed to increased triglyceride content in the fingermark samples. The ingredients of the foundation used by this donor did not include glycerides, but other components of both the foundation and the moisturiser may have a protective effect on fingermark glycerides, either through acting as a physical impediment to ageing processes, or by being preferentially degraded. For example, squalene, which can be present on human skin both as an endogenous component and as a cosmetic ingredient, is highly susceptible to oxidation processes, ${ }^{4,24,26,52}$ and may thereby slow the oxidation rate of the less reactive unsaturated lipids, including TGs. ${ }^{53,54}$

DG species continued to be detected as minor components of some samples throughout the 28 days, under both storage conditions. As TGs remained the predominant glyceride class in all samples regardless of age, it can be inferred that the hydrolysis of TGs to DGs and MGs is not a major degradation pathway of fingermark lipids. In a preliminary study, where samples were stored for up to 28 days wrapped in aluminium foil, no discernible changes in glyceride content were observed (data not shown). Glyceride profiles of the wrapped samples were much the same 28 days after deposition as after 1 day, indicating that exposure to air may be a more significant factor in glyceride degradation than exposure to light. Light exposure has been linked to increased degradation rates of fingermark compounds such as squalene. ${ }^{5,27}$ However, Pleik et al. inferred that the accelerated ozonolysis of monounsaturated TGs in samples exposed to light might instead be due to competing degradation mechanisms and additional environmental factors such as increased exposure to air flow. ${ }^{13}$ Similar observations were made by Hinners et al. who noted that the rate of TG ozonolysis was significantly reduced when fingermarks were stored in both clear and opaque containers, compared to samples left exposed to ambient air. ${ }^{55}$

\section{Oxidation products}

Due to the large volume of data obtained during data-independent acquisition, filtering of the data for candidate degradation products was limited to two mechanisms of TG oxidation: peroxidation and ozonolysis, as these pathways have been either identified as, or have been hypothesised to be, possible major pathways of fingermark glyceride degradation.

No compounds were identified that corresponded to ammoniated adducts of DG or TG hydroperoxides, or demonstrated neutral losses of peroxidised fatty acids. While Mong et al. proposed that fingermark glyceride oxidation occurs via similar processes to linseed oil, ${ }^{6}$ hydroperoxide formation is favoured in polyunsaturated fatty acids. ${ }^{45,46}$ Linseed oil, for example, is preferred as a drying oil due to its faster drying rate, which can be attributed to its high content of linolenic acid (FA 18:3). ${ }^{45}$ In human sebum, polyunsaturated fatty acids (primarily sebaleic acid and linoleic acid) are present in trace amounts in comparison to monounsaturated and saturated fatty acids. ${ }^{31,47}$ Monounsaturated fatty acids do not readily undergo autooxidation, ${ }^{56-58}$ but are susceptible to rapid reactions with ozone. ${ }^{53}$ The peroxidation rate of TGs has been observed to be much lower compared to other skin surface lipids (notably squalene and cholesterol). ${ }^{30}$ This would explain at least in part 
why ozonolysis appears to be a prevalent oxidation pathway of fingermark glycerides and their free fatty acids. ${ }^{13}$ Zhou et al. noted that triolein (TG 54:3) did not undergo degradation in the absence of ozone. ${ }^{53}$

A number of peaks with $\mathrm{m} / \mathrm{z}$ consistent with calculated [M+ $\left.\mathrm{NH}_{4}\right]^{+}$ions of TG ozonides (i.e. $48 \mathrm{Da}$ or $96 \mathrm{Da}$ greater than a known unsaturated TG) were identified in fingermark samples at all ageing times. These compounds eluted slightly earlier than the corresponding TGs, over a range of 13-16 minutes. This behaviour in a reversed-phase chromatography separation is consistent with the greater polarity of the oxidation products compared to their precursor lipids. ${ }^{59}$ Notably, a peak was observed at $\mathrm{m} / \mathrm{z} 870.7391$ that exhibited a neutral loss of FA $16: 1 ; \mathrm{O}_{3}+\mathrm{NH}_{3}$, which is consistent with the monoozonide of TG 48:1 (TG 48:1; $\mathrm{O}_{3}$ ) described by Pleik et al. ${ }^{13}$ By identifying peaks which exhibited the neutral loss of an ozonised fatty acid plus ammonia, several other candidate ozonides were identified. In total, 28 peaks were identified corresponding to mono- and diozonides derived from 23 TGs ranging from 40:1-57:1 in structure (Table 5). 17 of these precursor TGs were monounsaturated, while the remaining 6 were diunsaturated. Of these 23 TGs, 13 had been identified in previous work as common and abundant within a small donor population, ${ }^{49}$ from which the 5 donors involved in this study were sourced.

Collision-induced dissociation of TG ozonides was consistent with previous descriptions. ${ }^{13,50,53}$ Two major fragment types were observed, corresponding to the neutral loss of the ozonised fatty acid plus ammonia, and the neutral losses of a fatty acid plus ammonia, together with cleavage of the ozonide ring. Where one fragment of each type was observed in the high energy mass spectrum of a TG ozonide, a corresponding structure is proposed in Table 5. Structures were based on the assumption that the double bond (and therefore trioxolane) position is $\Delta 6$, with the exception of FA $18: 1 ; \mathrm{O}_{3}$, where the double bond position was assumed to be $\Delta 8$, as these are the most abundant positional isomers of each fatty acid in human sebum. ${ }^{3,31}$ However, this list is by no means exhaustive, as the high energy mass spectra were frequently complicated by multiple diagnostic fragments of one or both types due to coelution of isomeric TG ozonides, and so structures have not been suggested for many ozonides. This is not a surprising result, as sebaceous TGs have been shown to consist of a complex mixture of isomers. ${ }^{49,60}$

TG ozonides were frequently affected by peak splitting, which at least in part appeared to be a donor-dependent issue. Similar observations were made by Sun et al., who attributed this to the incomplete resolution of positional isomers of ozonides produced from a triolein standard.$^{50}$ Furthermore, different sections of the split TG ozonide peaks exhibited different product ions relating to the losses of different fatty acids containing the trioxolane ring (Fig. 3). Multiple ozonised fatty acid neutral losses, as well as multiple neutral losses of a fatty acid paired with cleavage of the trioxolane group, were also observed in the high energy mass spectra of TG ozonides that did not exhibit peak splitting. When TG ozonides eluted as peak clusters, specific data (e.g. retention time and MS data) is shown only for the peak section exhibiting the highest signal.

While sebaceous TGs consist of a number of polyunsaturated species, ${ }^{42,49,60}$ no ozonides were identified that could be attributed to TGs with more than two double bonds in this investigation, despite the detection of such lipids in the 1 day old samples. While this was initially thought to be due to the neutral loss filter, as di- and triozonides tend to be cleaved at the trioxolane ring, rather than undergo losses of the entire oxidised fatty acyl chain, ${ }^{50,53}$ no $\mathrm{m} / \mathrm{z}$ corresponding to $\left[\mathrm{M}+\mathrm{NH}_{4}\right]^{+}$ions of these ozonides were found. There are several possible explanations for this. Firstly, complete ozonolysis of a polyunsaturated species is progressive, with the monoozonides being the first oxidation products formed, before eventual total conversion to the fully oxidised lipid. ${ }^{13,50,53}$ As the number of possible ozonolysis intermediates increases with the number of double bonds, it could be that the division of a polyunsaturated TG across multiple oxidation products means that none of them demonstrated a sufficiently high signal for detection. Secondly, environmental factors might interfere with ozonide formation. It is accepted that 1,2,4-trioxolanes are produced by the reaction of ozone with a double bond via the Criegee mechanism, a three step process that involves the decomposition of an initial 1,2,3trioxolane, and rearrangement into a more stable configuration. ${ }^{50,61}$ However, the Criegee intermediates, zwitterions formed during the decomposition stage, can instead combine with other reactants to produce shorter chain products, form dimers, or undergo isomerisation to carboxylic acids. $^{24,26,50,61-63}$ In the presence of water (including humid reaction conditions) carbonyl and carboxylic acid derivatives can be formed from ozonolysis products, rather than a 1,2,4trioxolane. ${ }^{52,56,64-66}$ With increasing DB number, there are therefore more chances for interference in the secondary ozonide formation of an unsaturated TG. Zhou et al. observed that all trilolein ozonide signals were much lower if ozonolysis took place at $50 \%$ relative humidity (RH) compared to low humidity conditions. ${ }^{53}$ Throughout the 28-day ageing period in this study, samples in both storage conditions were exposed to increased humidity ( $c a .35-40 \% \mathrm{RH}$ ) during intermittent periods.

A number of peaks were observed with $\mathrm{m} / \mathrm{z}$ corresponding to that of a TG ozonide minus $172 \mathrm{Da}$, i.e. a possible aldehyde derivative of a 1,2,3-trioxolane, where cleavage at the $\Delta 6$ position had resulted in a loss of $\mathrm{C}_{10} \mathrm{H}_{20} \mathrm{O}_{2}$. Sun et al. observed that similar decomposition products were formed during ozonolysis of triolein, but did not report the fragmentation pattern of these compounds. ${ }^{50}$ The high energy mass spectra of the aldehyde derivatives observed in this study exhibited neutral losses of fatty acyl groups plus ammonia, as well as a loss of $147 \mathrm{Da}$, which can be attributed to the loss of the oxoacid chain $\left(\mathrm{C}_{6} \mathrm{H}_{10} \mathrm{O}_{3}\right)$ plus ammonia. Much like the TG ozonide peaks, these potential TG aldehyde derivatives were present as minor peaks in the 1-day old samples, but showed significantly higher relative peak signals in samples at 7 and 28 days following deposition. Similarly, other peaks were tenta- 
Table 5 Triglyceride ozonides detected in fingermarks from 5 donors

\begin{tabular}{|c|c|c|c|c|c|}
\hline & $\begin{array}{l}\text { Average retention } \\
\text { time (min) }\end{array}$ & $\begin{array}{l}\text { Average experimental } \mathrm{m} / \mathrm{z} \\
\left(\left[\mathrm{M}+\mathrm{NH}_{4}\right]^{+}\right)\end{array}$ & $\begin{array}{l}\text { Average CCS }\left(\AA^{2}\right) \\
\left(\left[\mathrm{M}+\mathrm{NH}_{4}\right]^{+}\right)\end{array}$ & $\begin{array}{l}\text { Observed ozonised fatty acid } \\
\text { neutral losses }\end{array}$ & Proposed structure(s) \\
\hline TG $40: 1 ; \mathrm{O}_{3}$ & 13.11 & 758.6140 & 302.7 & $\begin{array}{l}\text { FA } 14: 1 ; \mathrm{O}_{3} \\
\text { FA } 16: 1 ; \mathrm{O}_{3}\end{array}$ & - \\
\hline TG $42: 1 ; \mathrm{O}_{3}$ & 13.68 & 786.6455 & 310.2 & $\begin{array}{l}\text { FA } 14: 1 ; \mathrm{O}_{3} \\
\text { FA } 15: 1 ; \mathrm{O}_{3} \\
\text { FA } 16: 1 ; \mathrm{O}_{3} \\
\text { FA } 18: 1 ; \mathrm{O}_{3}\end{array}$ & TG 12:0_14:0_16:1; $\mathrm{O}_{3}$ \\
\hline TG $43: 1 ; \mathrm{O}_{3}$ & 13.95 & 800.6610 & 313.8 & $\begin{array}{l}\text { FA } 14: 1 ; \mathrm{O}_{3} \\
\text { FA } 16: 1 ; \mathrm{O}_{3}\end{array}$ & - \\
\hline TG $44: 1 ; \mathrm{O}_{3}$ & 14.15 & 814.6769 & 317.6 & $\begin{array}{l}\text { FA } 14: 1 ; \mathrm{O}_{3} \\
\text { FA } 15: 1 ; \mathrm{O}_{3} \\
\text { FA } 16: 1 ; \mathrm{O}_{3} \\
\text { FA } 17: 1 ; \mathrm{O}_{3}\end{array}$ & $\begin{array}{l}\text { TG 14:0_14:0_16:1; } \mathrm{O}_{3} \\
\text { TG 12:0_15:0_17:1; } \mathrm{O}_{3}\end{array}$ \\
\hline TG $45: 1 ; \mathrm{O}_{3}$ & 14.39 & 828.6922 & 321.5 & $\begin{array}{l}\text { FA } 14: 1 ; \mathrm{O}_{3} \\
\text { FA } 15: 1 ; \mathrm{O}_{3} \\
\text { FA } 16: 1 ; \mathrm{O}_{3} \\
\text { FA } 17: 1 ; \mathrm{O}_{3}\end{array}$ & TG 13:0_16:0_16:1; $\mathrm{O}_{3}$ \\
\hline TG $46: 1 ; \mathrm{O}_{3}$ & 14.56 & 842.7079 & 324.8 & $\begin{array}{l}\text { FA } 14: 1 ; \mathrm{O}_{3} \\
\text { FA } 15: 1 ; \mathrm{O}_{3} \\
\text { FA } 16: 1 ; \mathrm{O}_{3} \\
\text { FA } 17: 1 ; \mathrm{O}_{3} \\
\text { FA } 18: 1 ; \mathrm{O}_{3}\end{array}$ & TG 14:0_16:0_16:1; $\mathrm{O}_{3}$ \\
\hline TG $47: 1 ; \mathrm{O}_{3}$ & 14.76 & 856.7236 & 328.0 & $\begin{array}{l}\text { FA } 15: 1 ; \mathrm{O}_{3} \\
\text { FA } 16: 1 ; \mathrm{O}_{3} \\
\text { FA } 17: 1 ; \mathrm{O}_{3}\end{array}$ & TG 15:0_16:0_16:1; $\mathrm{O}_{3}$ \\
\hline TG $48: 1 ; \mathrm{O}_{3}$ & 14.93 & 870.7391 & 332.2 & $\begin{array}{l}\text { FA } 16: 1 ; \mathrm{O}_{3} \\
\text { FA } 17: 1 ; \mathrm{O}_{3} \\
\text { FA } 18: 1 ; \mathrm{O}_{3}\end{array}$ & $\begin{array}{l}\text { TG 16:0_16:0_16:1; } \mathrm{O}_{3} \\
\text { TG 14:0_16:0_18:1; } \mathrm{O}_{3}\end{array}$ \\
\hline TG $49: 1 ; \mathrm{O}_{3}$ & 15.07 & 884.7549 & 335.7 & $\begin{array}{l}\text { FA } 15: 1 ; \mathrm{O}_{3} \\
\text { FA } 16: 1 ; \mathrm{O}_{3}\end{array}$ & TG 16:0_17:0_16:1; $\mathrm{O}_{3}$ \\
\hline TG $50: 1 ; \mathrm{O}_{3}$ & 15.17 & 898.7705 & 339.6 & FA $18: 1 ; \mathrm{O}_{3}$ & TG 16:0_16:0_18:1; $\mathrm{O}_{3}$ \\
\hline TG $51: 1 ; \mathrm{O}_{3}$ & 15.32 & 912.7861 & 343.3 & $\begin{array}{l}\text { FA } 15: 1 ; \mathrm{O}_{3} \\
\text { FA } 16: 1 ; \mathrm{O}_{3} \\
\text { FA } 17: 1 ; \mathrm{O}_{3} \\
\text { FA } 18: 1 ; \mathrm{O}_{3}\end{array}$ & $\begin{array}{l}\text { TG 16:0_18:0_17:1; } \mathrm{O}_{3} \\
\text { TG 16:0_17:0_18:1;O} \mathrm{O}_{3}\end{array}$ \\
\hline TG 52:1; $\mathrm{O}_{3}$ & 15.47 & 926.8016 & 346.6 & $\begin{array}{l}\text { FA } 17: 1 ; \mathrm{O}_{3} \\
\text { FA } 18: 1 ; \mathrm{O}_{3}\end{array}$ & $\begin{array}{l}\text { TG 14:0_20:0_18:1; } \mathrm{O}_{3} \\
\text { TG 16:0_18:0_18:1; }{ }_{3} \\
\text { TG 17:0_17:0_18:1; }{ }_{3}\end{array}$ \\
\hline TG $53: 1 ; \mathrm{O}_{3}$ & 15.68 & 940.8184 & 350.7 & FA $16: 1 ; \mathrm{O}_{3}$ & 一 \\
\hline TG $54: 1 ; \mathrm{O}_{3}$ & 15.75 & 954.8332 & 352.5 & FA $18: 1 ; \mathrm{O}_{3}$ & TG 16:0_20:0_18:1; ${ }_{3}$ \\
\hline TG $55: 1 ; \mathrm{O}_{3}$ & 15.99 & 968.8493 & 355.8 & FA $16: 1 ; \mathrm{O}_{3}$ & - \\
\hline TG $56: 1 ; \mathrm{O}_{3}$ & 16.12 & 982.8653 & 359.2 & FA $16: 1 ; \mathrm{O}_{3}$ & - \\
\hline TG $57: 1 ; \mathrm{O}_{3}$ & 16.23 & 996.8803 & 363.3 & FA $16: 1 ; \mathrm{O}_{3}$ & - \\
\hline TG 46:2; $\mathrm{O}_{3}$ & 14.28 & 840.6930 & 320.4 & $\begin{array}{l}\text { FA } 14: 1 ; \mathrm{O}_{3} \\
\text { FA } 16: 1 ; \mathrm{O}_{3} \\
\text { FA } 18: 2 ; \mathrm{O}_{3}\end{array}$ & - \\
\hline TG $47: 2 ; \mathrm{O}_{3}$ & 14.47 & 854.7094 & 324.3 & FA $16: 1 ; \mathrm{O}_{3}$ & - \\
\hline TG 48:2; $\mathrm{O}_{3}$ & 14.66 & 868.7238 & 328.3 & FA $16: 1 ; \mathrm{O}_{3}$ & - \\
\hline TG 49:2; $\mathrm{O}_{3}$ & 14.81 & 882.7391 & 332.0 & $\begin{array}{l}\text { FA } 16: 1 ; \mathrm{O}_{3} \\
\text { FA } 18: 2 ; \mathrm{O}_{3}\end{array}$ & - \\
\hline TG $50: 2 ; \mathrm{O}_{3}$ & 14.96 & 896.7543 & 335.4 & $\begin{array}{l}\text { FA } 16: 1 ; \mathrm{O}_{3} \\
\text { FA } 18: 2 ; \mathrm{O}_{3}\end{array}$ & - \\
\hline TG $44: 2 ; \mathrm{O}_{6}$ & 13.06 & 860.6461 & 318.5 & FA $18: 2 ; \mathrm{O}_{6}$ & - \\
\hline TG 46:2; $\mathrm{O}_{6}$ & 13.53 & 888.6767 & 327.1 & FA $18: 2 ; \mathrm{O}_{6}$ & - \\
\hline TG $47: 2 ; \mathrm{O}_{6}$ & 13.78 & 902.6924 & 330.9 & FA $15: 1 ; \mathrm{O}_{3}$ & - \\
\hline TG 48:2; $\mathrm{O}_{6}$ & 13.96 & 916.7085 & 334.5 & FA $16: 1 ; \mathrm{O}_{3}$ & - \\
\hline TG 49:2; $\mathrm{O}_{6}$ & 14.04 & 930.7241 & 337.5 & FA $18: 2 ; \mathrm{O}_{6}$ & - \\
\hline TG $50: 2 ; \mathrm{O}_{6}$ & 14.24 & 944.7398 & 341.8 & FA $16: 1 ; \mathrm{O}_{3}$ & - \\
\hline
\end{tabular}

tively identified as carboxylic acid derivatives, possibly produced through further oxidation of the TG aldehyde derivatives or other intermediates produced via ozonolysis. The high energy mass spectra of the carboxylic acid derivatives exhibited neutral losses of fatty acyl groups plus ammonia, as well as the loss of the dicarboxylate chain $\left(\mathrm{C}_{6} \mathrm{H}_{10} \mathrm{O}_{4}\right)$ plus ammonia (163 Da). These fragmentation patterns are consistent with a recent report. ${ }^{55}$ Example high energy mass spectra and proposed structures are provided in Fig. 4.

Production of decanal, oxoacids and dicarboxylic acids via the oxidation of free fatty acids in latent fingermarks has been previously described, ${ }^{3}$ and it follows that glycerides would degrade in a similar manner. While Hinners et al. reported both TG aldehyde and carboxylic acid derivatives from latent 


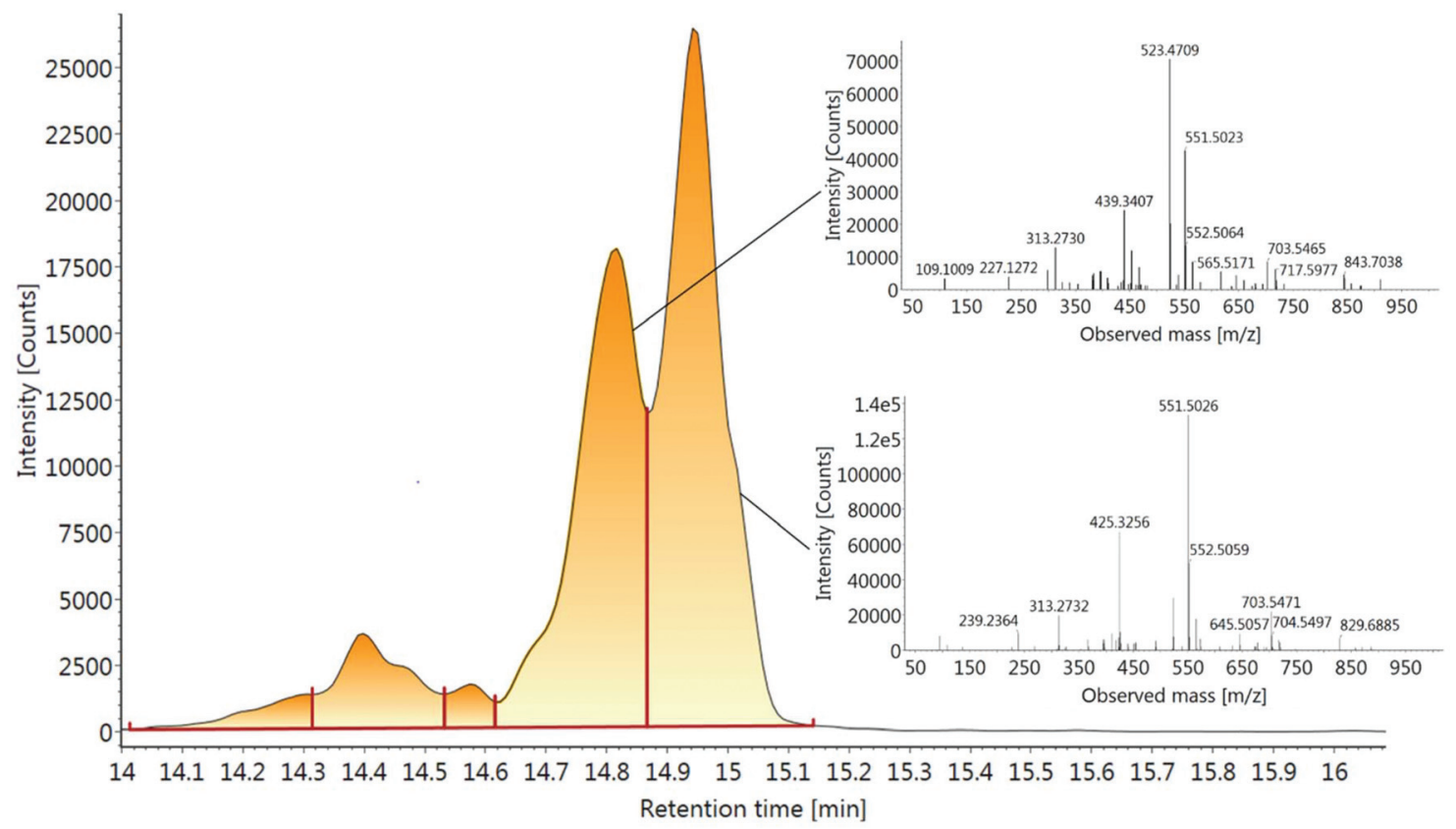

Fig. 3 Extracted ion chromatogram of $\mathrm{m} / \mathrm{z} 870.7392\left(48: 1 ; \mathrm{O}_{3}\right)$, with inset high energy mass spectra of isomers eluting at $14.81 \mathrm{~min}$ (top) and $14.95 \mathrm{~min}$ (bottom) demonstrating primary neutral losses of FA 18:1; $\mathrm{O}_{3}+\mathrm{NH}_{3}(\mathrm{~m} / \mathrm{z} 523)$ and FA 16:1; $\mathrm{O}_{3}+\mathrm{NH}_{3}(\mathrm{~m} / z$ 552), respectively.

a)

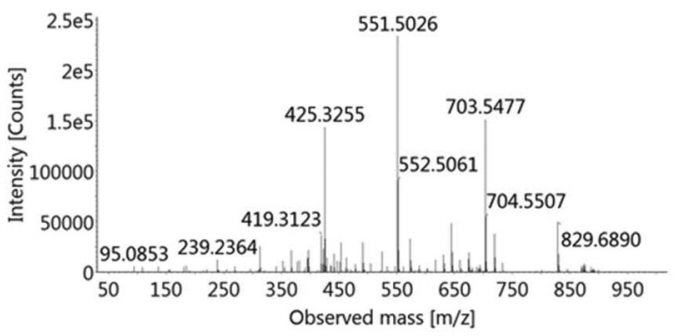

b)

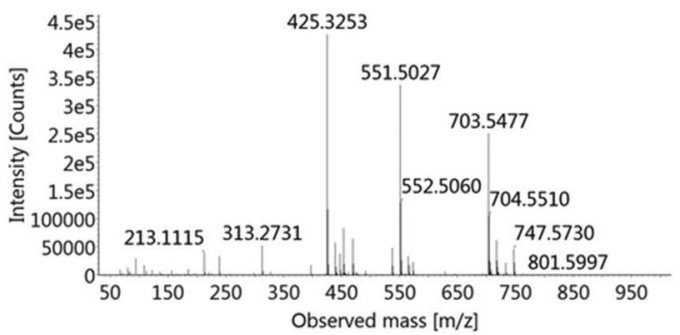

c)

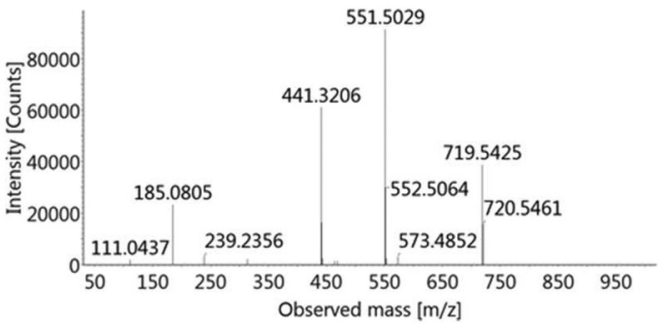

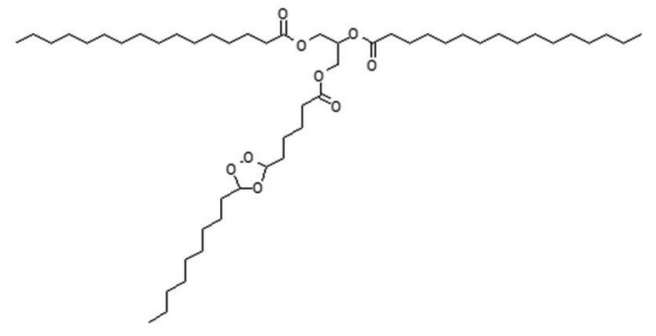
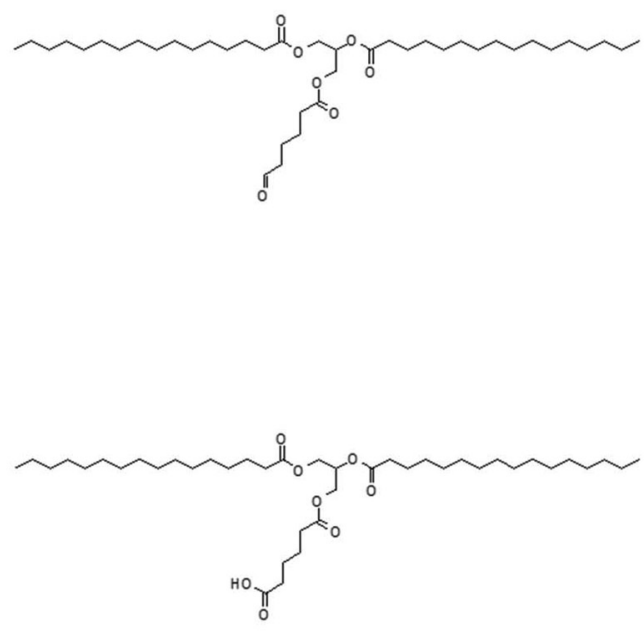

Fig. 4 High energy mass spectra with example structures of TG 48:1 degradation products (a) monoozonide $(\mathrm{m} / \mathrm{z} 870)$, (b) aldehyde derivative $(\mathrm{m} / \mathrm{z}$ 698 ) and (c) carboxylic acid derivative $(\mathrm{m} / \mathrm{z} 714)$. 


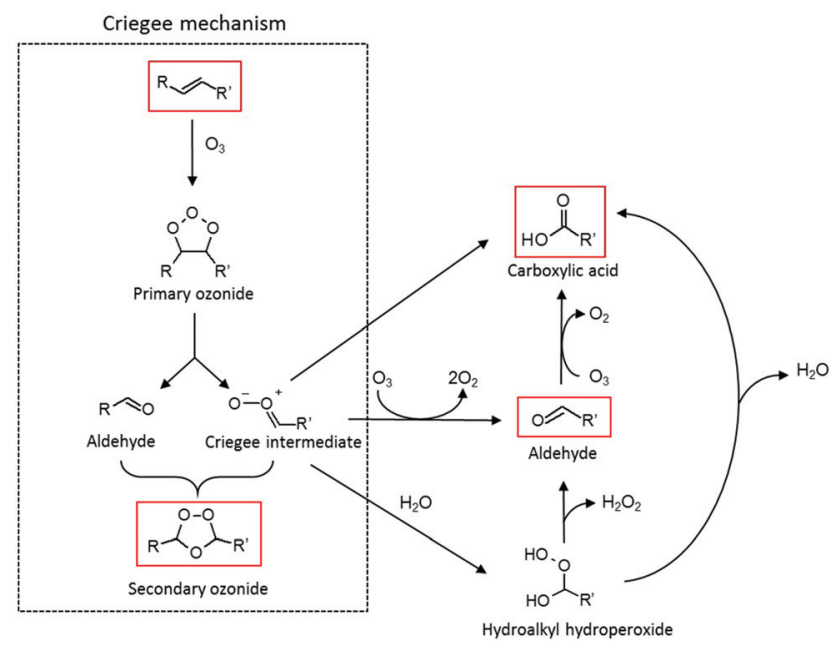

Fig. 5 Proposed reaction mechanisms for unsaturated triglycerides with ozone. Structures observed in this study are outlined in red. Based on ref. $53,61-63,65$ and 66 .

fingermark samples, they identified them as being products of in-source decomposition of secondary ozonides, which were not detected by the MALDI-MS method employed. ${ }^{55}$ Possible reaction schemes for the formation of all TG ozonolysis products observed in this study are summarised in Fig. 5. Further investigation is required to confirm the identities of these peaks, and whether these are indeed decomposition products formed during TG ozonolysis.

TG ozonides identified at all ageing periods in this investigation are summarised in Table 6. While TG ozonides were identified in samples at all time intervals during this investigation, ozonides were identified as only minor components in 1 day old samples from 4 of the 5 donors, relative to the peak areas of the unoxidised TGs. As more recently deposited samples were not analysed, it is unclear as to whether these ozonides formed after sample collection, or whether they were already present on the donors' skin, as part of the initial fingermark residue. It may be a continuous process, as lipid ozonolysis has been observed to take place rapidly on human skin when deliberately exposed to ozone..$^{24,26}$ Monoozonides of TGs 44:1-50:1 were identified in almost every sample 7 days and older as major sample components, which is an unsurprising result given that the parent TGs comprised the most common and abundant fingermark glycerides in the 1 day old samples. This is consistent with the significant signal reduction of unsaturated TGs described above.

Ozonides of diunsaturated TGs were detected as both mono- and diozonides at different ageing times throughout this investigation. Only monoozonides of these particular TGs were identified in samples extracted 1 day after deposition. Both mono-and diozonides were identified in 7 day old samples, however, monoozonides were identified less frequently compared to the 1 day old samples. Finally, only diozonides were identified in samples extracted after 28 days, regardless of whether samples had been stored with or
Table 6 Qualitative profiles of triglyceride ozonides detected in fingermarks from 5 donors as a function of sample age

\begin{tabular}{|c|c|c|c|c|}
\hline \multirow[b]{2}{*}{$\mathrm{CN}: \mathrm{DBE} ; \mathrm{O}_{x}$} & \multicolumn{4}{|c|}{$\begin{array}{l}\text { Number of fingermarks }[n=15] \text { (number of donors }[n \\
=5] \text { ) }\end{array}$} \\
\hline & Day 1 & Day 7 & Day 28 (desk) & Day 28 (drawer) \\
\hline $40: 1 ; \mathrm{O}_{3}$ & $1(1)$ & $4(2)$ & $5(2)$ & $3(1)$ \\
\hline $42: 1 ; \mathrm{O}_{3}$ & $2(1)$ & $11(5)$ & $7(4)$ & $8(4)$ \\
\hline $43: 1 ; \mathrm{O}_{3}$ & - & $10(4)$ & $10(4)$ & $12(5)$ \\
\hline $44: 1 ; \mathrm{O}_{3}$ & $3(3)$ & $13(5)$ & $14(5)$ & $14(5)$ \\
\hline $45: 1 ; \mathrm{O}_{3}$ & $1(1)$ & $15(5)$ & $15(5)$ & $15(5)$ \\
\hline $46: 1 ; \mathrm{O}_{3}$ & $5(3)$ & $15(5)$ & $15(5)$ & $15(5)$ \\
\hline $47: 1 ; \mathrm{O}_{3}$ & $7(3)$ & $15(5)$ & $15(5)$ & $15(5)$ \\
\hline $48: 1 ; \mathrm{O}_{3}$ & $6(3)$ & $13(5)$ & $14(5)$ & $15(5)$ \\
\hline $49: 1 ; \mathrm{O}_{3}$ & $2(1)$ & $14(5)$ & $13(5)$ & $14(5)$ \\
\hline $50: 1 ; \mathrm{O}_{3}$ & 1 (1) & $12(5)$ & $13(5)$ & $14(5)$ \\
\hline $51: 1 ; \mathrm{O}_{3}$ & - & $13(5)$ & $11(5)$ & $11(5)$ \\
\hline $52: 1 ; \mathrm{O}_{3}$ & - & $9(5)$ & $6(4)$ & $10(4)$ \\
\hline $53: 1 ; \mathrm{O}_{3}$ & - & $2(1)$ & $3(2)$ & - \\
\hline $54: 1 ; \mathrm{O}_{3}$ & $1(1)$ & 3 (1) & $5(3)$ & $2(1)$ \\
\hline $55: 1 ; \mathrm{O}_{3}$ & - & $5(3)$ & $6(3)$ & $6(3)$ \\
\hline $56: 1 ; \mathrm{O}_{3}$ & - & $4(3)$ & $7(3)$ & $6(4)$ \\
\hline $57: 1 ; \mathrm{O}_{3}$ & - & $2(2)$ & $2(1)$ & $3(2)$ \\
\hline $46: 2 ; \mathrm{O}_{3}$ & $4(2)$ & - & - & - \\
\hline $47: 2 ; \mathrm{O}_{3}$ & $3(2)$ & $2(1)$ & - & - \\
\hline $48: 2 ; \mathrm{O}_{3}$ & $9(3)$ & $1(1)$ & - & - \\
\hline $49: 2 ; \mathrm{O}_{3}$ & $4(2)$ & $1(1)$ & - & - \\
\hline $50: 2 ; \mathrm{O}_{3}$ & $5(2)$ & $1(1)$ & - & - \\
\hline $44: 2 ; \mathrm{O}_{6}$ & - & - & $1(1)$ & $3(1)$ \\
\hline $46: 2 ; \mathrm{O}_{6}$ & - & $4(4)$ & $1(1)$ & $1(1)$ \\
\hline $47: 2 ; \mathrm{O}_{6}$ & - & $3(2)$ & - & $1(1)$ \\
\hline $48: 2 ; \mathrm{O}_{6}$ & - & $4(3)$ & $1(1)$ & $6(3)$ \\
\hline $49: 2 ; \mathrm{O}_{6}$ & - & $4(3)$ & - & $7(3)$ \\
\hline $50: 2 ; \mathrm{O}_{6}$ & - & $2(1)$ & - & $3(3)$ \\
\hline
\end{tabular}

without exposure to light. The concurrent detection of diozonides in samples 7 days and older indicates the progressive reaction of ozone with polyunsaturated TGs to their fully ozonated counterparts between 7-28 days of ageing. ${ }^{13,53}$ However, the most common and abundant TG ozonides identified in fingermarks at all time periods investigated through this study were monoozonides of monounsaturated TGs.

As shown in Table 6, greater numbers of TG diozonides were identified in samples stored in the drawer for 28 days, compared to those stored on the desk for the same period of time. Zhou et al. recently reported that exposure to UV light through a closed office window led to rapid degradation of the triozonide of a triolein standard, whereas light-protected samples (covered in aluminium foil) remained relatively stable. ${ }^{53}$ In this study, samples stored on the desk were exposed to direct sunlight on several occasions throughout this investigation; during clear mornings samples were directly illuminated for several hours through an adjacent office window. However, the bulk fingermark residue may physically or chemically protect ozonides from degradation. ${ }^{13}$ Individual lipid standards deposited onto a surface exhibit faster reaction rates compared to analogous lipids within fingermark samples stored under the same conditions. ${ }^{13,18}$ Additionally, Pleik et al. reported that ozonolysis products were not detected in fingermarks stored in a wooden desk drawer for up to 63 days. ${ }^{13}$ This could be due to the substrate used for sample collection, 
as filter paper would absorb a greater quantity of fingermark residue than the aluminium foil used by Pleik et al. Other possible explanations may include differences in storage conditions (i.e. materials and dimensions of the drawers used in each study, as well as airtightness and external airflow) that might impact the availability of ozone to react with fingermark lipids. However, it must be borne in mind that only small donor populations were used in these studies, and that fingermark composition exhibits high intra-donor variability. As no quantification approach was used here, it is uncertain as to how light exposure, or other environmental factors, quantitatively impact the persistence of fingermark TGs or their ozonides.

\section{Conclusions}

The degradation processes of latent fingermark components are of great interest to forensic research, from the perspective of evaluating their impact on detection, as well as the potential to estimate the age of a latent fingermark. The glyceride fraction constitutes a diverse range of structures, which presents difficulties not only for their identification, but for monitoring degradation pathways and identifying their products. Using UPLC-IMS-QTOF-MS ${ }^{\mathrm{E}}$, mono- and diozonides of 23 fingermark triglycerides were identified as oxidation products formed over a 28 day period. The progressive oxidation of diunsaturated triglycerides to mono- and diozonides was observed to take place in latent fingermarks for the first time, through changes in qualitative profiles at 7 and 28 days after deposition. Ozonolysis of latent fingermark lipids produces a mixture of oxidation products and isomers, reflecting the complexity of the initial glyceride composition. While ozonides have been previously identified in latent fingermarks, this is the first time that a data-independent acquisition approach has been reported, with ozonides being identified simultaneously alongside di- and triglycerides that were characterised in previous work. Additionally, aldehyde and carboxylic acid derivatives were identified as other possible degradation products formed through side reactions with ambient humidity.

The results of this investigation support the hypothesis that ozone is the major reactant involved in TG degradation in latent fingermark residue. Further work is required to determine the impact of other environmental factors, such as humidity, on glyceride degradation, as well as investigating the stability and possible further degradation of TG ozonides. Such fundamental information is required to enable better understanding of lipid-sensitive fingermark detection techniques, and to assess the potential of ozonolysis as a basis for estimating fingermark age.

\section{Conflicts of interest}

There are no conflicts to declare.

\section{Acknowledgements}

The authors would like to thank all of the fingermark donors for their participation, as well as Dr Dieter Kirsch (Bundeskriminalamt, Wiesbaden, Germany) and Dr Gerhard Liebisch (University Hospital Regensburg, Regensburg, Germany) for useful discussions relating to this research. This project was funded by the Swiss National Science Foundation (205121_169677) and approved by Swissethics (2017-00265). Informed consent was obtained from all donors prior to sample collection.

\section{References}

1 S. Cadd, et al., Fingerprint composition and aging: A literature review, Sci. Justice, 2015, 55(4), 219-238.

2 A. Girod, et al., Aging of target lipid parameters in fingermark residue using GC/MS: Effects of influence factors and perspectives for dating purposes, Sci. Justice, 2016, 56(3), 165-180.

3 S. Pleik, et al., Fatty Acid Structure and Degradation Analysis in Fingerprint Residues, J. Am. Soc. Mass Spectrom., 2016, 27(9), 1565-1574.

4 K. A. Mountfort, et al., Identification of oxidation products of squalene in solution and in latent fingerprints by ESI-MS and LC/APCI-MS, Anal. Chem., 2007, 79(7), 26502657.

5 N. E. Archer, et al., Changes in the lipid composition of latent fingerprint residue with time after deposition on a surface, Forensic Sci. Int., 2005, 154(2-3), 224-239.

6 G. M. Mong, C. E. Petersen and T. R. W. Clauss, Advanced Fingerprint Analysis Project: Fingerprint Constituents, Pacific Northwest National Laboratory, Richland, 1999.

7 K. M. Antoine, et al., Chemical differences are observed in children's versus adults' latent fingerprints as a function of time, J. Forensic Sci., 2010, 55(2), 513-518.

8 P. O. Andersson, et al., Towards Fingermark Dating: A Raman Spectroscopy Proof-of-Concept Study, ChemistryOpen, 2017, 6(6), 706-709.

9 A. Girod, C. Roux and C. Weyermann, La datation des traces digitales (partie II): proposition d'une approche formelle, Rev. Int. Criminol. Police Tech. Sci., 2014, 67(2), 226249.

10 A. Girod, et al., Fingermark initial composition and aging using Fourier transform infrared microscopy (u-FTIR), Forensic Sci. Int., 2015, 254, 185-196.

11 S. Oonk, et al., Proteomics as a new tool to study fingemark ageing in forensics, Sci. Rep., 2018, 8, 16425.

12 A. Koenig, A. Girod and C. Weyermann, Identification of wax esters in latent print residues by gas chromatographymass spectrometry and their potential use as ageing parameters, J. Forensic Identif., 2011, 61(6), 652-676.

13 S. Pleik, et al., Ambient-air ozonolysis of triglycerides in aged fingerprint residues, Analyst, 2018, 143(5), 1197-1209. 
14 K. Baniuk, Determination of age of fingerprints, Forensic Sci. Int., 1990, 46(1-2), 133-137.

15 P. D. Barnett and R. A. Berger, The effects of temperature and humidity on the permamency of latent fingerprints, J. Forensic Sci., 1977, 16(3), 249-254.

16 C. Weyermann, C. Roux and C. Champod, Initial results on the composition of fingerprints and its evolution as a function of time by GC/MS analysis, J. Forensic Sci., 2011, 56(1), 102-108.

17 S. Bleay and M. De Puit, Ageing of fingermarks, in Fingerprint Development Techniques: Theory and Application, Wiley, 2018, pp. 69-97.

18 B. N. Dorakumbura, F. Busetti and S. W. Lewis, Analysis of squalene and its transformation by-products in latent fingermarks by ultrahigh-performance liquid chromatography-high resolution accurate mass Orbitrap $^{\mathrm{TM}}$ mass spectrometry, Forensic Chem., 2020, 17, 100193.

19 B. N. Dorakumbura, T. Becker and S. W. Lewis, Nanomechanical mapping of latent fingermarks: A preliminary investigation into the changes in surface interactions and topography over time, Forensic Sci. Int., 2016, 267, 1624.

20 J. De Alcaraz-Fossoul, et al., Latent Fingermark Aging Patterns (Part III): Discontinuity Index as One Indicator of Degradation, J. Forensic Sci., 2018, 62(5), 1180-1187.

21 K. C. O'Neill and Y. J. Lee, Effect of Aging and Surface Interactions on the Diffusion of Endogenous Compounds in Latent Fingerprints Studied by Mass Spectrometry Imaging, J Forensic Identif., 2018, 63(3), 708-713.

22 R. Ramotowski, Lipid Reagents, in Lee and Gaensslen's Advances in Fingerprint Technology, ed. R. Ramotowski, CRC Press, Boca Raton, 2012, pp. 83-96.

23 C. Lennard, Fingerprint detection: future prospects, Aust. J. Forensic Sci., 2007, 39(2), 73-80.

24 A. Wisthaler and C. J. Weschler, Reactions of ozone with human skin lipids: Sources of carbonyls, dicarbonyls, and hydroxycarbonyls in indoor air, Proc. Natl. Acad. Sci. U. S. A., 2010, 107(15), 6568-6575.

25 L. S. Pandrangi and G. C. Morrison, Ozone interactions with human hair: Ozone uptake rates and product formation, Atmos. Environ., 2008, 42(20), 5079-5089.

26 S. Zhou, et al., Rapid Oxidation of Skin Oil by Ozone, Environ. Sci. Technol. Lett., 2016, 3(4), 170-174.

27 A. A. Frick, et al., Monitoring compositional changes of the lipid fraction of fingermark residues deposited on paper during storage, Forensic Chem., 2016, 2, 29-36.

28 S. Ekanayake Mudiyanselage, et al., Ultraviolet A induces generation of squalene monohydroperoxide isomers in human sebum and skin surface lipids in vitro and in vivo, J. Invest. Dermatol., 2003, 120(6), 915-922.

29 N. Hayashi, et al., Effect of sunlight exposure and aging on skin surface lipids and urate, Exp. Dermatol., 2003, 12(s2), 13-17.

30 M. Picardo, et al., Role of skin surface lipids in UV-induced epidermal cell changes, Arch. Dermatol. Res., 1991, 283(3), 191-197.
31 N. Nicolaides, Skin lipids: their biochemical uniqueness, Science, 1974, 186(4158), 19-26.

32 R. Ramotowski, Composition of Latent Print Residue, in Advances in Fingerprint Technology, ed. H. Lee and R. Gaensslen, CRC Press, Boca Raton, 2001, pp. 63-104.

33 J. Salama, et al., Evaluation of the Fingermark Reagent Oil Red $\mathrm{O}$ as a Possible Replacement for Physical Developer, J. Forensic Identif., 2008, 58(2), 203-237.

34 M. de la Hunty, et al., Understanding physical developer (PD): Part I - Is PD targeting lipids?, Forensic Sci. Int., 2015, 257, 481-487.

35 R. R. Marples, et al., The role of the aerobic microflora in the genesis of fatty acids in human surface lipids, J. Invest. Dermatol., 1970, 55(3), 173-178.

36 A. R. Shalita, Genesis of free fatty acids, J. Invest. Dermatol., 1974, 62(3), 332-335.

37 D. T. Downing, Lipolysis by human skin surface debris in organic solvents, J. Invest. Dermatol., 1970, 54, 395-398.

38 A. L. Byrd, Y. Belkaid and J. A. Segre, The human skin microbiome, Nat. Rev. Microbiol., 2018, 16, 143-155.

39 E. A. Grice and J. A. Segre, The skin microbiome, Nat. Rev. Microbiol., 2011, 9, 244-253.

40 N. Goetz, et al., Analysis of the lipid content of single hair bulbs. Comparison with the content of the sebaceous glands and with surface lipids, Int. J. Cosmet. Sci., 1984, 4(2), 39-52.

$41 \mathrm{~K}$. Phan, et al., Retrieving forensic information about the donor through bacterial profiling, Int. J. Leg. Med., 2019, 134(1), 21-29.

42 E. Camera, et al., Comprehensive analysis of the major lipid classes in sebum by rapid resolution high-performance liquid chromatography and electrospray mass spectrometry, J. Lipid Res., 2010, 51, 3377-3388.

43 R. Michael-Jubeli, J. Bleton and A. Baillet-Gufroy, Hightemperature gas chromatography-mass spectrometry for skin surface lipids profiling, J. Lipid Res., 2011, 52, 143155.

44 T. Sadowski, et al., Large-scale human skin lipidomics by quantitative, high-throughput shotgun mass spectrometry, Sci. Rep., 2017, 7, 43761.

45 M. Lazzari and O. Chiantore, Drying and oxidative degradation of linseed oil, Polym. Degrad. Stab., 1999, 65(2), 303313.

46 M. Gomez, D. Reggio and M. Lazzari, Linseed oil as a model system for surface enhanced Raman spectroscopy detection of degradation products in artworks, J. Raman Spectrosc., 2019, 50(2), 242-249.

47 A. Johnston and K. Rogers, The Effect of Moderate Temperatures on Latent Fingerprint Chemistry, Appl. Spectrosc., 2017, 71(9), 2102-2110.

48 E. Niki, Lipid oxidation in the skin, Free Radical Res., 2015, 49(7), 827-834.

49 A. A. Frick and C. Weyermann, An untargeted lipidomic approach for qualitative determination of latent fingermark glycerides using UPLC-IMS-QToF-MS ${ }^{\mathrm{E}}$, Analyst, 2019, 144(11), 3590-3600. 
50 C. Sun, Y. Zhao and J. M. Curtis, A study of the ozonolysis of model lipids by electrospray ionization mass spectrometry, Rapid Commun. Mass Spectrom., 2012, 26(8), 921930.

51 G. Liebisch, et al., Shorthand notation for lipid structures derived from mass spectrometry, J. Lipid Res., 2013, 54(6), 1523-1530.

52 S. Zhou, M. W. Forbes and J. P. D. Abbatt, Kinetics and Products from Heterogeneous Oxidation of Squalene with Ozone, Environ. Sci. Technol., 2016, 50(21), 11688-11697.

53 Z. Zhou, S. Zhou and J. Abbatt, Kinetics and Condensedphase Products in Multiphase Ozonolysis of an Unsaturated Triglyceride, Environ. Sci. Technol., 2019, 53(21), 12467-12475.

54 M. A. Dessì, et al., Oxidative stability of polyunsaturated fatty acids: effect of squalene, Eur. J. Lipid Sci. Technol., 2002, 104(8), 506-512.

55 P. Hinners, M. Thomas and Y. J. Lee, Determining Fingerprint Age with Mass Spectrometry Imaging via Ozonolysis of Triacylglycerols, Anal. Chem., 2020, 92(4), 3125-3132.

56 W. A. Pryor, G. L. Squadrito and M. Friedman, The cascade mechanism to explain ozone toxicity: The role of lipid ozonation products, Free Radicals Biol. Med., 1995, 19(6), 935941.

57 R. Cueto, G. L. Squadrito and W. A. Pryor, Quantifying aldehydes and distinguishing aldehydic product profiles from autoxidation and ozonation of unsaturated fatty acids, Methods Enzymol., 1994, 233, 174-182.

58 A. Zeb, Chemistry and liquid chromatography methods for the analyses of primary oxidation products of triacylglycerols, Free Radical Res., 2015, 49(5), 549-564.
59 W. E. Neff and W. C. Byrdwell, Characterization of model triacylglycerol (triolein, trilinolein and trilinolenin) autoxidation products via high-performance liquid chromatography coupled with atmospheric pressure chemical ionization mass spectrometry, J. Chromatogr., A, 1998, 818(2), 169-186.

60 B. Emerson, et al., Laser Desorption/Ionization Time-ofFlight Mass Spectrometry of Triacylglycerols and Other Components in Fingermark Samples, J. Forensic Sci., 2011, 56(2), 381-389.

61 R. Criegee, Mechanism of Ozonolysis, Angew. Chem., Int. Ed. Engl., 1975, 14(11), 745-752.

62 L. Vereecken, H. Harder and A. Novelli, The reactions of Criegee intermediates with alkenes, ozone, and carbonyl oxides, Phys. Chem. Chem. Phys., 2014, 16(9), 4039-4049.

63 T. S. Omonov, E. Kharraz and J. M. Curtis, Ozonolysis of Canola Oil: A Study of Product Yields and Ozonolysis Kinetics in Different Solvent Systems, J. Am. Oil Chem. Soc., 2011, 88(5), 689-705.

64 N. U. Soriano, V. P. Migo and M. Matsumura, Ozonation of Sunflower Oil: Spectroscopic Monitoring of the Degree of Unsaturation, J. Am. Oil Chem. Soc., 2003, 80(10), 997-1001.

65 Y. Chu, et al., Effect of Ozone Concentration and Relative Humidity on the Heterogeneous Oxidation of Linoleic Acid Particles by Ozone: An Insight into the Interchangeability of Ozone Concentration and Time, ACS Earth Space Chem., 2019, 3(5), 779-788.

66 N. Heine, F. A. Houle and K. R. Wilson, Connecting the Elementary Reaction Pathways of Criegee Intermediates to the Chemical Erosion of Squalene Interfaces during Ozonolysis, Environ. Sci. Technol., 2017, 51(23), 1374013748. 